\title{
Structural tailing and pyroelectric energy harvesting of P(VDF-TrFE) and P(VDF- TrFE-CTFE) ferroelectric polymer Blends
}

\author{
Mudassar Shehzad, ${ }^{\dagger} \uparrow$ and Yaojin Wang ${ }^{\dagger, *}$ \\ ${ }^{\dagger}$ School of Materials Science and Engineering, Nanjing University of Science and Technology, Nanjing 210094, Jiangsu, \\ China \\ ¥School of Chemical and Materials Engineering, National University of Sciences and Technology (NUST) H-12, Islamabad, \\ 46000, Pakistan
}

\section{Supplementary figures}
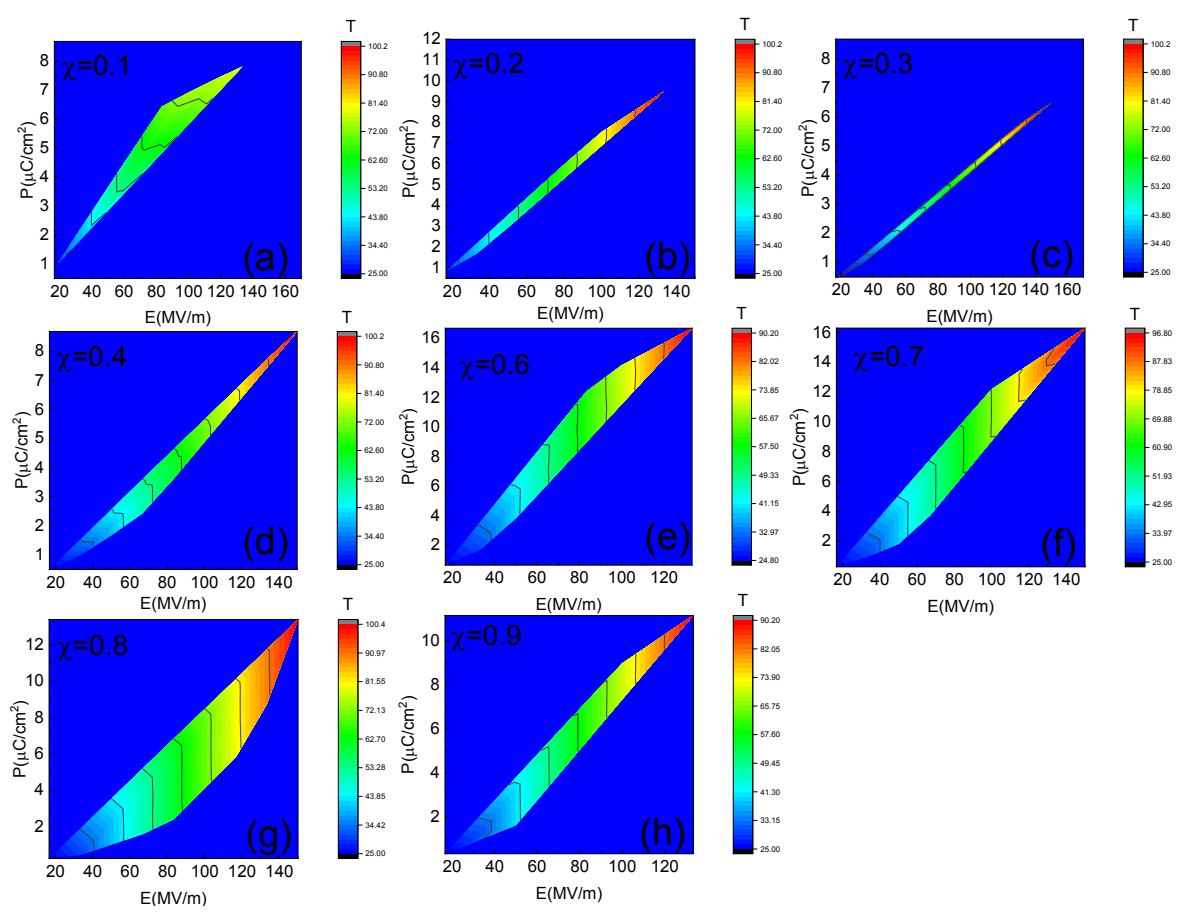

Figure S1 (a-h) shows the Polarization-Electric filed and Temperature contour graph for $\chi=0.1$, $0.2,0.3,0.4, \ldots 0.9$ blends. 

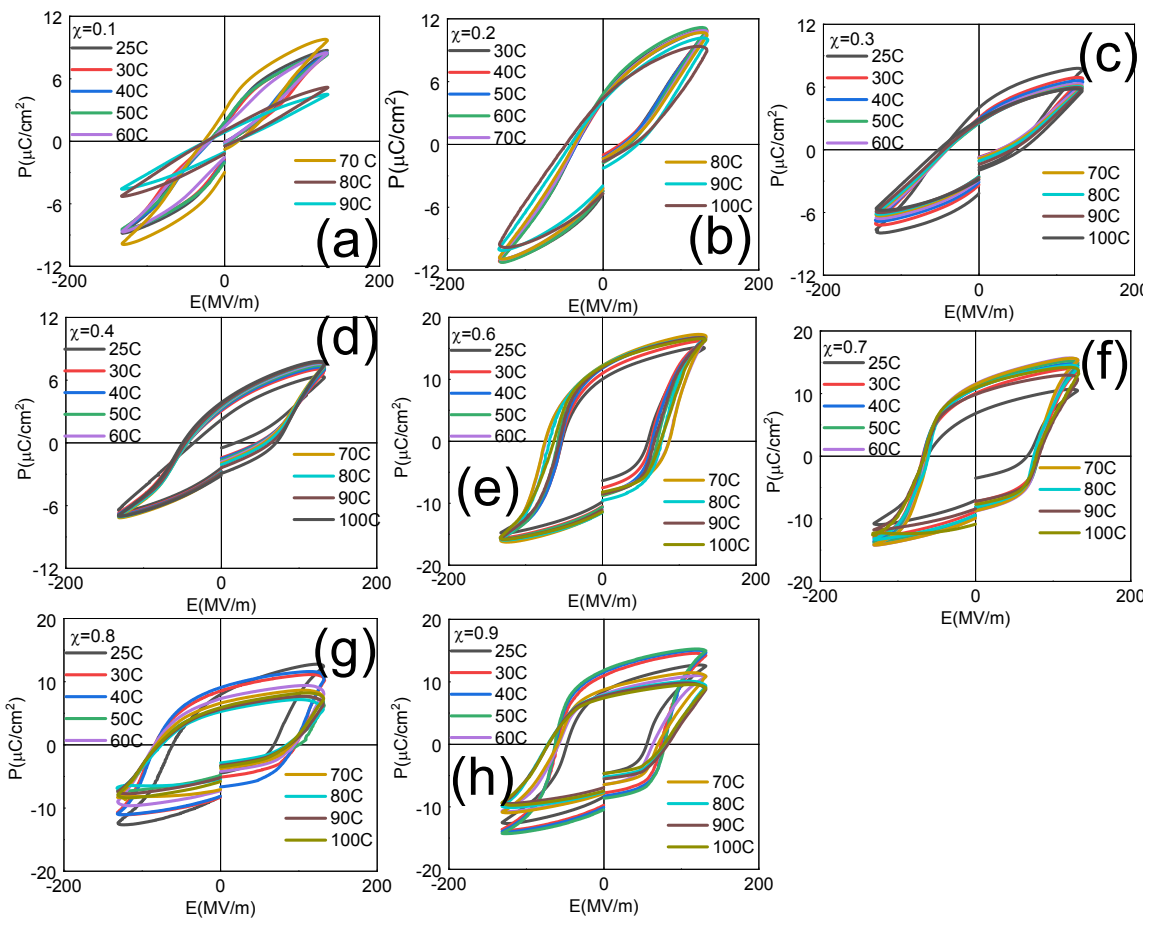

Figure S2 shows P-E hysteresis loop at $\mathrm{E}=133.33 \mathrm{MV} / \mathrm{m}$ at $100 \mathrm{~Hz}$ frequency at various temperatures. (a-h) The temperature dependent hysteresis loops of $\chi=0.1$ to 0.9 blends
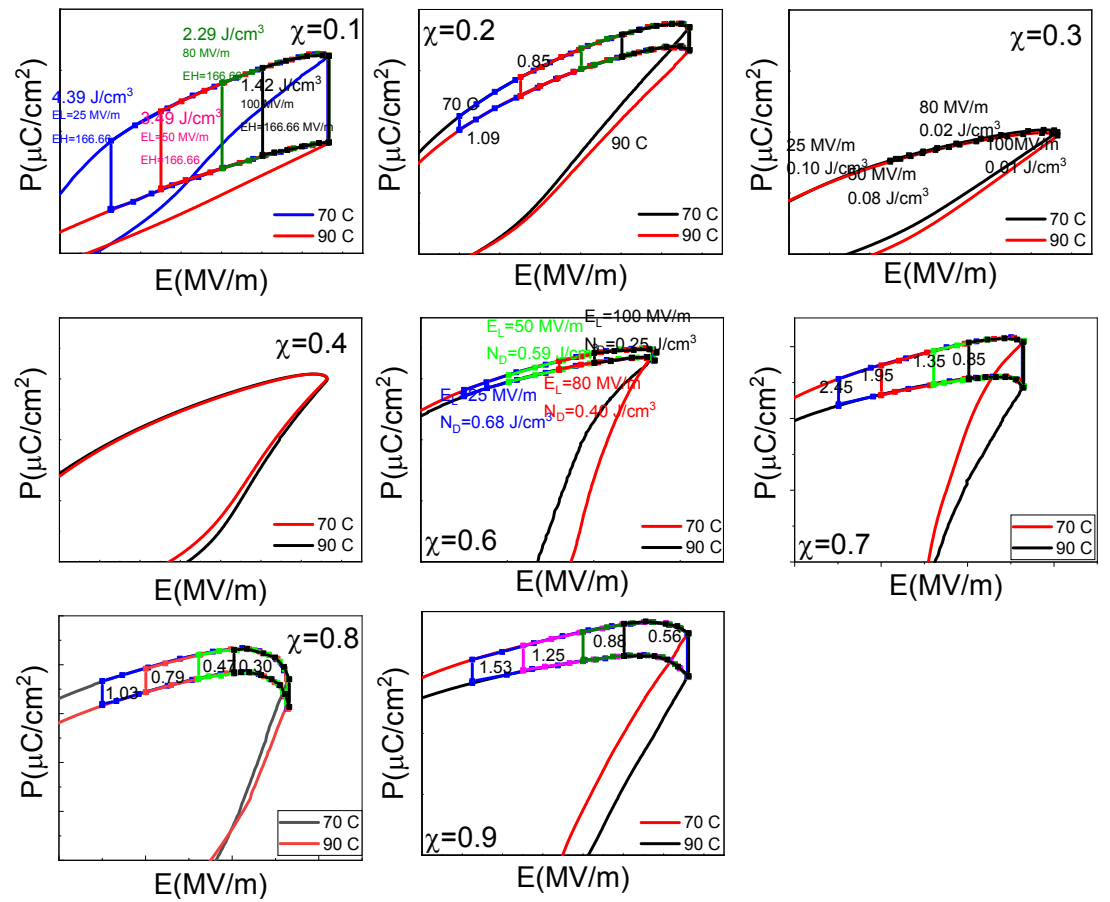

Figure $\mathrm{S} 3$ shows Olsen power cycle for $\chi=0.1$ to $\chi=0.9$ blends $\mathrm{E}_{\mathrm{L}}=0 \mathrm{MV} / \mathrm{m} \mathrm{E}_{\mathrm{H}}=133.33 \mathrm{MV} / \mathrm{m}$ from $70{ }^{\circ} \mathrm{C}$ to $90{ }^{\circ} \mathrm{C}$ at $100 \mathrm{~Hz}$. 